\title{
Corticotropin-Releasing Factor Receptors Modulate Oxytocin Release in the Dorsolateral Bed Nucleus of the Stria Terminalis (BNST) in Male Rats
}

\author{
Daisy Martinon ${ }^{1}$ and Joanna Dabrowska ${ }^{1,2 *}$ \\ ${ }^{1}$ Department of Cellular and Molecular Pharmacology, Chicago Medical School, Rosalind Franklin University of Medicine and \\ Science, North Chicago, IL, United States, ${ }^{2}$ Department of Neuroscience, Chicago Medical School, Rosalind Franklin \\ University of Medicine and Science, North Chicago, IL, United States
}

OPEN ACCESS

Edited by:

James A. Carr

Texas Tech University, United States

Reviewed by:

Balazs Gaszner,

University of Pécs, Hungary

Patrick J. Ronan,

Veterans Health Administration (VHA),

United States

James William Crane,

University of Tasmania, Australia

*Correspondence:

Joanna Dabrowska

joanna.dabrowska@rosalindfranklin.edu

Specialty section

This article was submitted to Neuroendocrine Science,

a section of the journal

Frontiers in Neuroscience

Received: 01 December 2017 Accepted: 06 March 2018

Published: 21 March 2018

Citation:

Martinon D and Dabrowska J (2018)

Corticotropin-Releasing Factor Receptors Modulate Oxytocin Release in the Dorsolateral Bed Nucleus of the

Stria Terminalis (BNST) in Male Rats.

Front. Neurosci. 12:183.

doi: 10.3389/fnins.2018.00183
The neuropeptide oxytocin (OT) plays an important role in the regulation of social and anxiety-like behavior. Our previous studies have shown that OT neurons send projections from the hypothalamus to the dorsolateral bed nucleus of the stria terminalis $\left(B N S T_{d l}\right.$ ), a forebrain region critically involved in the modulation of anxiety-like behavior. Importantly, these OT terminals in the BNST $\mathrm{dll}_{\text {ll }}$ express presynaptic corticotropin releasing factor (CRF) receptor type 2 (CRFR2). This suggests that CRFR2 might be involved in the modulation of OT release. To test this hypothesis, we measured OT content in microdialysates collected from the BNST $\mathrm{dll}_{\text {ll }}$ of freely-moving male Sprague-Dawley rats following the administration of a selective CRFR2 agonist (Urocortin 3) or antagonist (Astressin 2B, As2B). To determine if type 1 CRF receptors (CRFR1) are also involved, we used selective CRFR1 antagonist (NBI35965) as well as CRF, a putative ligand of both CRFR1 and CRFR2. All compounds were delivered directly into the BNST dl via reverse dialysis. OT content in the microdialysates was measured with highly sensitive and selective radioimmunoassay. Blocking CRFR2 with As2B caused an increase in OT content in BNST $\mathrm{d}_{\mathrm{d}}$ microdialysates, whereas CRFR2 activation by Urocortin 3 did not have an effect. The As2B-induced increase in OT release was blocked by application of the CRFR1 antagonist demonstrating that the effect was dependent on CRFR1 transmission. Interestingly, CRF alone caused a delayed increase in OT content in BNST dl microdialysates, which was dependent on CRF2 but not CRF1 receptors. Our results suggest that members of the CRF peptide family modulate OT release in the BNST dl via a fine-tuned mechanism that involves both CRFR1 and CRFR2. Further exploration of mechanisms by which endogenous OT system is modulated by CRF peptide family is needed to better understand the role of these neuropeptides in the regulation of anxiety and the stress response.

Keywords: oxytocin, CRF, urocortin, BNST, bed nucleus of the stria terminalis, release, microdialysis 


\section{INTRODUCTION}

Oxytocin (OT) is a hormone and a neuromodulator produced by neurons in the paraventricular (PVN), supraoptic (SON), and accessory nuclei of the hypothalamus (Sofroniew, 1983; Swanson and Sawchenko, 1983). Central OT neurotransmission is involved in a wide array of social behaviors, including but not limited to, pair bond formation, social recognition, and the onset of maternal behavior (Pedersen et al., 1992; Bosch and Young, 2017). Growing evidence suggests that OT is involved in the regulation of the stress response. For example, OT inhibits hypothalamic-pituitary-adrenal (HPA) axis activity in both male and female rats (Neumann et al., 2000). While the exact mechanisms by which OT regulates stress reactivity are not known, direct interaction between the OT and corticotropinreleasing factor (CRF) systems may substantially impact affective behavior as well as the response to stress. However, little is known about how the CRF-OT systems interact at either in the PVN or extra-hypothalamic sites.

In the 1980's, Bruhn and colleagues showed that intracerebroventricular (ICV) administration of CRF greatly elevates plasma OT levels in rats, without affecting argininevasopressin (AVP) secretion (Bruhn et al., 1986), suggesting that central CRF receptor activation could modulate OT secretion. Arima and Aguilera reported that CRFR2 mRNA is co-expressed with OT mRNA in rat SON (Arima and Aguilera, 2000), and we have found similar co-expression of CRFR2, both mRNA and protein, in OT neurons of the rat PVN (Dabrowska et al., 2011). CRF gene expression was significantly enhanced in response to restraint stress in the PVN of OT-deficient mice (Nomura et al., 2003) suggesting that OT secretion can, conversely, impact CRF expression. More recently, activation of the OTR in the PVN was shown to delay transcription of the gene encoding CRF (Jurek et al., 2015), and OT was shown to reduce excitatory synaptic transmission into CRF neurons in the PVN (Jamieson et al., 2017). These studies might provide possible mechanisms for OT regulation of the stress response.

OT neurons are capable of releasing OT from their soma and dendrites in the PVN and SON (Pow and Morris, 1989) as well as from their axons and axon terminals (Ebner et al., 2005). OT fibers originating from the hypothalamus have been found in several brain regions, including the central nucleus of the amygdala (CeA), the lateral septum (LS), and the bed nucleus of the stria terminalis (BNST) (Ebner et al., 2005; Veenema and Neumann, 2008; Dabrowska et al., 2011; Knobloch et al., 2012). Previously, we have shown that OT immunoreactivity in the dorsolateral BNST (BNST $\mathrm{dl}_{\mathrm{d}}$ ) is restricted to fibers characterized by multiple-beaded varicosities, indicative of possible release sites and axon terminals, which originate, at least partially, from the PVN (Dabrowska et al., 2011). We have also shown that these OT-positive fibers express CRF receptor type 2 (CRFR2). Using electron microscopy we have shown presynaptic localization of CRFR2 on axon terminals that contain dense core vesicles in the BNST $_{\mathrm{dl}}$ (Dabrowska et al., 2011). These findings suggest that CRFR2 might play a role in the regulation of OT release in the $\mathrm{BNST}_{\mathrm{dl}}$.
The effects of CRF-peptide family members are mediated by two receptors: CRFR1 and CRFR2 (Chalmers et al., 1995; Lovenberg et al., 1995), which can be activated by the endogenous peptides, Urocortin (Ucn) 1, 2, and 3 as well as CRF (Hauger et al., 2003a). Ucn3 is the most potent and selective CRFR2 agonist of all, whereas Ucn1 has high affinity for both CRF1 and CRFR2 (Lewis et al., 2001; Suda et al., 2004). CRF has approximately a 17-fold greater affinity toward CRFR1 than CRFR2 (Hauger et al., 2003b); therefore only elevated levels of CRF would be expected to activate both CRFR2 and CRFR1, e.g., following stress. Recently, we have shown that CRFR2 is also present on OT terminals in the nucleus accumbens shell $(\mathrm{NaC})$ of male prairie voles, where it suppresses OT release and is involved in social loss-induced passive coping behavior (Bosch et al., 2016). BNST $\mathrm{dl}_{\mathrm{d}}$ is a key brain area translating stress into sustained anxiety, and has one of the highest densities of oxytocin fibers in the rodent brain (Dabrowska et al., 2011; Knobloch et al., 2012), yet the factors that regulate OT release in the $\mathrm{BNST}_{\mathrm{dl}}$ are not known. In the current study, we use microdialysis in freely moving rats to demonstrate that OT release in the $\mathrm{BNST}_{\mathrm{dl}}$ is modulated by members of the CRF peptide family delivered directly into the $\mathrm{BNST}_{\mathrm{dl}}$ via reverse dialysis. We demonstrate that CRF receptors in the $\mathrm{BNST}_{\mathrm{dl}}$ play distinct roles in the modulation of OT release such as CRFR2 has inhibitory influence on OT release, whereas intact CRFR1 transmission is necessary for stimulation of OT release in the $\mathrm{BNST}_{\mathrm{dl}}$.

\section{METHODS}

\section{Animals}

Male Sprague-Dawley rats (Envigo, Chicago, IL; 240-300 g at the time of surgery) were housed in groups of 3 with a $12 / 12 \mathrm{~h}$ lightdark cycle and acclimated to the vivarium for at least 7 days before surgery. Protocols for animal experiments in this study were performed in accordance with the guidelines of the National Institute of Health and were approved by the Animal Care and Use Committee at Rosalind Franklin University of Medicine and Science (IACUC protocol \# B13-29 and \# 17-04). A total of 79 rats were used in the experiments, and nine rats were excluded from the analysis due to probe misplacement or inability to unequivocally confirm placement of the probe. Seventy rats total were included in the analysis.

\section{Stereotaxic Surgery}

The two ends of the microdialysis probe were first attached with PE-20 polyethylene tube, followed by flushing and filling of the probe with sterile double distilled water. Standard stereotaxic procedures (Moaddab and Dabrowska, 2017) were used for unilateral implantation of the microdialysis probe. Rats were implanted with probe containing U-shape dialysis membrane (molecular cut-off $18 \mathrm{kDa}$, Hemophan, Gambro Dialysatoren, Hechingen, Germany), for details see Neumann et al., 1993 into the $\mathrm{BNST}_{\mathrm{dl}}$ (coordinates from Bregma: AP $+0.1 \mathrm{~mm}, \mathrm{ML}+3.4 \mathrm{~mm}, \mathrm{DV}-7.25 \mathrm{~mm}, 15^{\circ}$ coronal angle). Due to transient unavailability of $\mathrm{U}$-shape probes, one group of rats (treated with As2B+CRF, $n=6$ and ACSF, $n=3$ ) was 
implanted with concentric dialysis membrane: molecular cut-off 50 kDa (Brainlink, Groningen, Netherlands, see Results section for analysis of baseline OT content in $\mathrm{BNST}_{\mathrm{dl}}$ microdialysates collected with the two types of probes). The length of the microdialysis probes' membrane was $1 \mathrm{~mm}$ from the bottom of the shaft to the tip of the membrane. Rats were given an analgesic ( $5 \mathrm{mg} / \mathrm{kg}$ ketoprofen, subcutaneous) prior to the surgery. The surgery was performed with a stereotaxic frame (David Kopf Instruments, USA) using isoflurane anesthesia (EZ Systems Corporation, Palmer, PA). One group of rats $(n=19)$ was anesthetized during surgery with IP injection of a cocktail dexdormitor $(0.25 \mathrm{mg} / \mathrm{kg}$ ) and ketamine $(75 \mathrm{mg} / \mathrm{kg}$ ) (Henry Schein, Henry Schein Animal Health, Dublin, OH). We have not observed any significant differences in OT levels between rats anesthetized during surgery with the dexdormitor/ketamine cocktail or isoflurane (see Results section for details). Small stainless steel screws were inserted into the frontal and parietal bones to secure the probe to the skull using acrylic cement. At the end of surgery, the outlets of the probe were secured with tape to prevent any damage to the probe until the day of the experiment. Ketoprofen was given again the morning after surgery. Rats were caged individually for 2 days prior to starting the microdialysis experiment. This has been shown to be an optimal timeline as chronic implantation of the microdialysis probe increases the risk of gliosis 3 days after implantation, which significantly reduces absolute and relative recovery of the microdialysis membrane (Hascup et al., 2009).

\section{Microdialysis}

Rats were placed individually in Plexiglas chambers $(43 \times$ $21 \times 31 \mathrm{~cm}$ ) for $30 \mathrm{~min}$ before connecting the probe to the microinjection pump. The rat was gently restrained and the microdialysis probe was connected to a $3 \mathrm{ml}$ syringe mounted on a microdialysis pump (PHD Ultra Pump, Harvard Apparatus) using a 2-channel spiral tubing (CT-20, Eicom, San Diego, CA, internal volume $4 \mu \mathrm{l}$ ) with connecting Joint Teflon (JT10, Eicom, San Diego, CA, $4 \mu \mathrm{l}$ ) and a 2-way swivel (Eicom, San Diego, CA). Hence, total internal volume of inlet and outlet tubing was $16 \mu \mathrm{l}$ so that any treatment effects could be observed in the first sample collected after the drug infusion. This microdialysis study was performed in awake, freely moving rats that were provided with food and water for the duration of the experiment. The microdialysis probes were perfused $(3.33 \mu \mathrm{l} / \mathrm{min}$ ) with sterile Artificial Cerebral Spinal Fluid (ACSF composition: $20 \mathrm{mM} \mathrm{NaCl}, 3.5 \mathrm{mM} \mathrm{KCl}, 1.1 \mathrm{mM} \mathrm{KH_{2 }} \mathrm{PO}_{4}$, $1.3 \mathrm{mM} \mathrm{MgCl}_{2}, 2.5 \mathrm{mM} \mathrm{CaCl}_{2}, 20 \mathrm{mM}$ glucose, $30 \mathrm{mM} \mathrm{NaHCO}_{3}$, $0.4 \mathrm{mM}$ ascorbate, $0.8 \mathrm{mM}$ thiourea, $2 \mathrm{mM}$ Na-pyruvate, $\mathrm{pH}$ adjusted to 7.4 ) for $1 \mathrm{~h}$ microdialysis probe equilibration, during which no samples were collected. Following the collection of three 30 -min $(100 \mu \mathrm{l}$ each) baseline samples vehicle (ACSF) or vehicle combined with drugs was infused at a flow rate of $1 \mu \mathrm{l} / \mathrm{min}$ for $15 \mathrm{~min}$ using $1 \mathrm{ml} \mathrm{BD} \mathrm{U}-100$ insulin syringe mounted on a microinjection pump. The slower perfusion rate during this phase of the experiment produced no significant accumulation of OT content in the group perfused only with ACSF (see Results section for details). The flow rate was then restored to $3.33 \mu \mathrm{l} / \mathrm{min}$ for another $25 \mathrm{~min}$ and $100 \mu \mathrm{l}$ samples were collected in each group. Five more, $30 \mathrm{~min}(100 \mu \mathrm{l})$ microdialysate samples were collected while perfusing ACSF only at $3.33 \mu \mathrm{l} / \mathrm{min}$. All the samples were collected in $1.5-\mathrm{ml}$ low-retention Eppendorf tubes placed on ice and immediately frozen on dry ice after collection and then stored at $-80^{\circ} \mathrm{C}$. Rats were individually housed for the duration of the microdialysis experiment. Each rat was used only once in the microdialysis experiment and received only one treatment. Experimental timeline is shown on Figure 1.

\section{Pharmacological Manipulations}

CRFR2 agonist, Urocortin 3 (mouse) trifluroacetate (Ucn3) and CRF acetate salt (human, rat, synthetic) were purchased from Bachem (catalog number $\mathrm{H}-5828$ and $\mathrm{H}-2435$, respectively, Torrance, CA). CRFR2 antagonist, Astressin-2B (As2B) and CRFR1 antagonist (NBI 35965) were purchased from Tocris (2391 and 3100, respectively, Minneapolis, MN). Drugs were infused at a concentration of $10 \mu \mathrm{M}$, a dose that was proven effective in previous microdialysis studies (Ji and Neugebauer, 2007; Wang et al., 2007). Additionally, As2B dose was established based on its efficacy demonstrated on CeA slices during electrophysiological recordings (Pollandt et al., 2006). Drug concentration needed in the microdialysis probe $(10 \mu \mathrm{M})$ is considered $\sim 100$ times higher than effective concentration used in the tissue slice $(100 \mathrm{nM})$, due to the concentration gradient across the dialysis membrane and diffusion in the tissue ( $\mathrm{Li}$ and Neugebauer, 2004a,b).

Microdialysates were collected in 30-min intervals, with 3baseline samples followed by pharmacological challenge: $\mathrm{Ucn} 3$ ( $n$ $=7)$, As2B $(n=14), \mathrm{CRF}(n=9), \mathrm{As} 2 \mathrm{~B}+\mathrm{CRF}(n=7), \mathrm{As} 2 \mathrm{~B}+$ NBI $35965(n=6), \mathrm{CRF}+\mathrm{NBI} 35965(n=8)$, and ACSF $(n$ =19). All the compounds (CRF, As2B, Ucn3, NBI 35965) have molecular weights below $5 \mathrm{kDa}$ (respectively 4757.52, 4041.69, 4172.97, and $437.79 \mathrm{~g} / \mathrm{mol}$ ); and therefore could be delivered via retrodialysis with microdialysis probes with cut-off of 18 $\mathrm{kDa}$ (U-shape) and $50 \mathrm{kDa}$ (concentric). On any experimental day, treatment groups were counterbalanced such as at least one vehicle-infused rat was accompanied by at least two more rats from respective treatment groups (e.g., As2B alone, and As2B + $\mathrm{CRF}$ ). A pH test strip was used to determine if there was any change in $\mathrm{pH}$ after adding the drug to the ACSF.

\section{Probe Placement}

Following microdialysis, the rats were deeply anesthetized with isoflurane, the probes were perfused with Chicago Sky Blue $6 \mathrm{~B}$ dye (Alfa Aesar, Ward Hill, MA) as a $2 \%$ solution in $0.9 \%$ saline, and the animals were euthanized by decapitation. All extracted brains were frozen, then sliced $(50 \mu \mathrm{m})$ and photographed to confirm proper placement of the probe (Figure 1). Microdialysates from experimental subjects with correctly placed probes were analyzed for OT content. Proper probe placement met the following criteria: cannula tip located in the $\mathrm{BNST}_{\mathrm{dl}}$ (Bregma $+0.10 \mathrm{~mm}$ to Bregma $-0.36 \mathrm{~mm}$ ), above the anterior commissure, below the lateral ventricle and medially to the internal capsule (as indicated in Figure 1A). Due to a small number of rats confirmed as negative controls based on unequivocal cannula misplacement (Figure 1), microdialysates from these rats were not analyzed $(n=4)$. 


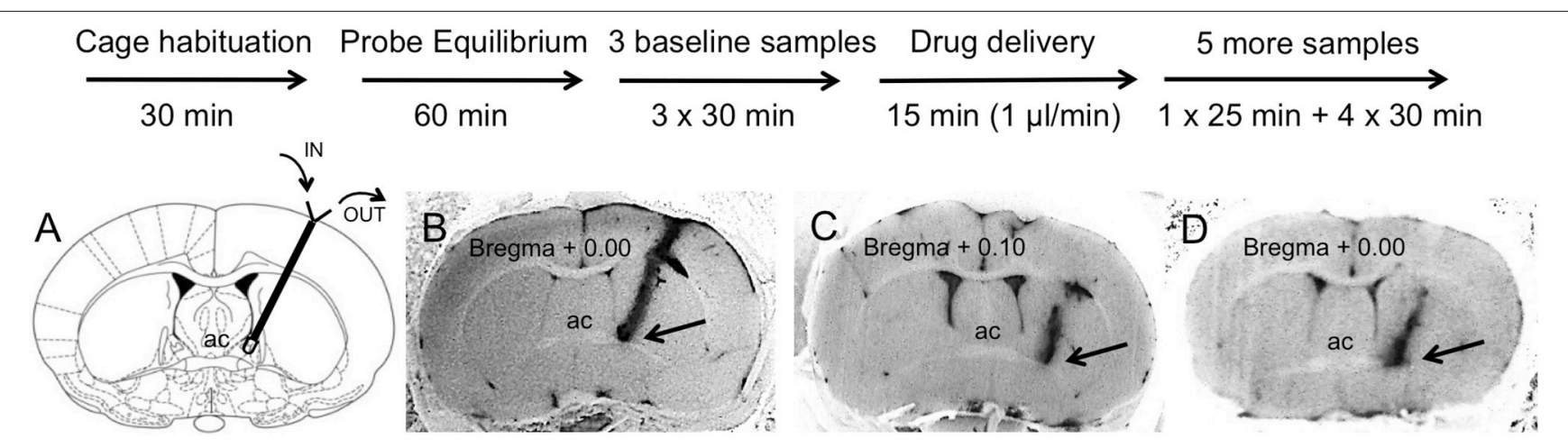

FIGURE 1 | Experimental timeline (upper panel) and representative brain sections with a track of microdialysis probe targeting BNST dil (bottom panel). Upon completion of the microdialysis experiments the probes were perfused with Chicago Sky Blue 6B dye. All extracted brains were sliced and all BNST sections were

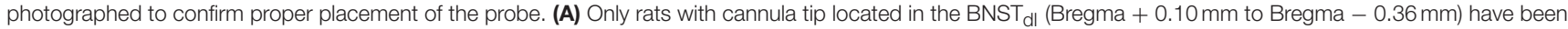
included in the analysis. Modified from Paxinos and Watson (2009). (B) An example of confirmed cannula location in the BNST dl, which met the following criteria: above the anterior commissure (ac), below the lateral ventricle and medially to the internal capsule as indicated by the arrow (included in the analysis). (C) An example

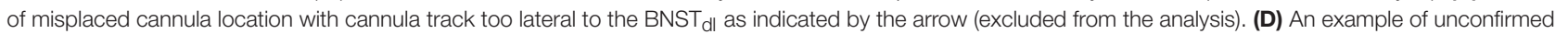
cannula location due to inability to see the tip of the cannula as indicated by the arrow (excluded from the analysis).

\section{Radioimmunoassay for OT}

The frozen dialysates samples were evaporated to dryness in a vacuum concentrator (Jouan RC10.10, Thermo Fisher Scientific) with a freeze dry system (FreeZone 6, LABCONCO). All evaporated microdialysates were treated identically. The content of OT in each dialysate was quantified with a highly sensitive (0.1 pg OT/100 $\mu \mathrm{l}$ sample) and selective radioimmunoassay (RIA, minimal affinity for arginine-vasopressin, RIAgnosis, Munich, Germany), as described previously (Neumann et al., 1993; Ross et al., 2009; Bosch et al., 2016). Cross-reactivity of the polyclonal antiserum with arginine-vasopressin and other related peptides was $<0.7 \%$. Intra- and inter-assay coefficients of variation were $<8$ and $<11 \%$, respectively. Due to the high total number of microdialysis samples (560), microdialysates were analyzed during four RIAs and each assay contained balanced number of samples from different treatment groups.

\section{Statistics}

Data are presented as mean \pm standard error of mean (SEM) of OT content in $\mathrm{BNST}_{\mathrm{dl}}$ microdialysates expressed as pg per $100 \mu l$ sample (Table 1). Data sets were first analyzed for normal distribution using D'Agostino \& Pearson omnibus normality test. Data demonstrated normal distribution $(P>0.05)$, and was analyzed using parametric tests. Results were first analyzed by within group one-way repeated measures analysis of variance (ANOVA) for each treatment group. Where the F-ratio was significant, all-pairwise post-hoc comparisons were made using Bonferroni's tests by comparing the mean of each time point (post-treatment) with the mean of the three baseline samples (pre-treatment). F ratio (DFn, DFd) referred to two degrees of freedom, where DFn $=\mathrm{a}-1$, whereas DFd $=\mathrm{N}-\mathrm{a}$. " $\mathrm{A}$ " was the number of groups and " $\mathrm{N}$ " was the total number of subjects in all groups. Since the sphericity (equal variability of differences) was not assumed in one-way repeated measures ANOVA, the GeisserGreenhouse correction resulted in smaller degrees of freedom, which were not integers.
For between treatment groups' analysis, data are presented as percentage changes from baseline \pm SEM. Here, OT content in microdialysates for each rat was expressed as percentage change from its own baseline values (mean of three baseline samples, $100 \%$ ) for each time point measured. Here, results were analyzed by two-way repeated measures ANOVA with the factors TIME (measured after a drug infusion) and TREATMENT (ACSF, Ucn3, As2B, CRF, As2B + CRF, As2B + NBI 35965, CRF + NBI 35965). Where the F-ratio was significant, all-pairwise post-hoc comparisons were made using Bonferroni's tests.

OT content in two subsequent microdialysates (before and after reduction of the perfusion rate) in control rats perfused with ACSF only was compared using a paired $t$-test. Baseline OT contents in BNST $_{\mathrm{dl}}$ microdialysates collected in rats implanted with U-shape vs. Brainlink probes were compared using an unpaired $t$-test. The effect of type of anesthesia used during surgery on OT content in $\mathrm{BNST}_{\mathrm{dl}}$ microdialysates was also analyzed using an unpaired $t$-test. The statistical analyses were completed using GraphPad Prism version 6.0 (GraphPad Software Inc., San Diego, CA). $P<0.05$ was considered significant.

\section{RESULTS}

\section{OT Content in BNST ${ }_{d l}$ Microdialysates Following CRFR Modulation -Within Group Analysis}

Baseline OT content in the $\mathrm{BNST}_{\mathrm{dl}}$ from all rats had an average \pm SEM of $1.18 \pm 0.05$ pg. OT content $(\mathrm{pg} / 100 \mu \mathrm{l})$ in $\mathrm{BNST}_{\mathrm{dl}}$ microdialysates, including three baseline samples, is shown in Table 1 for all treatment groups. First, to determine if OT content in baseline $\mathrm{BNST}_{\mathrm{dl}}$ microdialysates was stable before any treatment was introduced; we have compared oxytocin content between three baseline microdialysates in all rats for each treatment group with one-way repeated measures ANOVA. 
TABLE 1 | CRFR manipulation affects OT content in BNST dll microdialysates.

\begin{tabular}{|c|c|c|c|c|c|c|c|c|}
\hline $\begin{array}{l}\text { Treatment ( } n \text { per group) OT } \\
\text { pg } / 100 \mu \mathrm{I} \text { MEAN } \pm \text { SEM }\end{array}$ & Baseline 1 & Baseline 2 & Baseline 3 & $30 \mathrm{~min}$ & $60 \mathrm{~min}$ & $90 \mathrm{~min}$ & $120 \mathrm{~min}$ & $150 \mathrm{~min}$ \\
\hline $\operatorname{ACSF}(n=19)$ & $1.07 \pm 0.05$ & $1.03 \pm 0.05$ & $1.04 \pm 0.06$ & $1.04 \pm 0.11$ & $0.94 \pm 0.04$ & $0.93 \pm 0.07$ & $0.92 \pm 0.06$ & $0.87 \pm 0.07$ \\
\hline $\operatorname{CRF}(n=9)$ & $0.96 \pm 0.17$ & $1.08 \pm 0.20$ & $1.02 \pm 0.14$ & $1.12 \pm 0.26$ & $1.06 \pm 0.19$ & $1.30 \pm 0.23$ & $1.01 \pm 0.20$ & $1.07 \pm 0.23$ \\
\hline $\operatorname{Ucn} 3(n=7)$ & $1.32 \pm 0.10$ & $1.68 \pm 0.20$ & $1.30 \pm 0.11$ & $1.73 \pm 0.16$ & $1.52 \pm 0.11$ & $1.57 \pm 0.09$ & $1.25 \pm 0.06$ & $1.25 \pm 0.10$ \\
\hline As2B+NBI $35965(n=6)$ & $0.81 \pm 0.09$ & $0.98 \pm 0.07$ & $1.02 \pm 0.10$ & $0.88 \pm 0.08$ & $0.93 \pm 0.03$ & $0.87 \pm 0.07$ & $0.92 \pm 0.12$ & $0.91 \pm 0.12$ \\
\hline
\end{tabular}

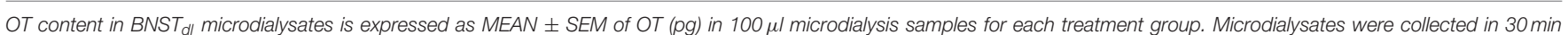

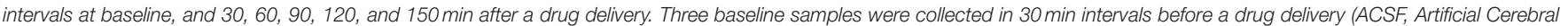

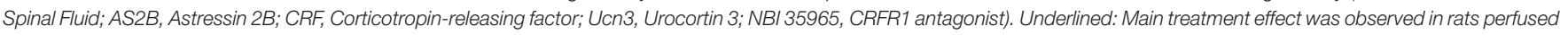

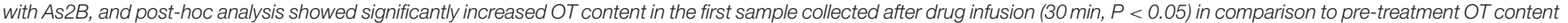
(Bonferroni's multiple comparisons).

We found that OT content did not differ between baseline microdialysates in ACSF $\left[F_{(1.823,31.00)}=0.0536, P=0.93\right]$, As2B $\left[F_{(1.229,11.06)}=0.0684, P=0.85\right], \operatorname{Ucn} 3\left[F_{(1.450,7.249)}=1.895\right.$, $P=0.22]$, CRF $\left[F_{(1.844,14.75)}=0.7142, P=0.49\right], \mathrm{CRF}+$ As2B $\left[F_{(1.947,11.68)}=0.0609, P=0.94\right]$, As2B + NBI 35965 $\left[F_{(1.489,7.444)}=1.482, P=0.28\right]$, and CRF + NBI 35965-treated groups $\left[F_{(1.185,8.296)}=3.541, P=0.09\right]$.

We then compared OT content in $\mathrm{BNST}_{\mathrm{dl}}$ microdialysates within each treatment group with one-way repeated measures ANOVA. No significant effect of treatment was observed in rats perfused with ACSF only $\left[F_{(2.972,53.50)}=1.477, P=0.23\right.$, Figure 2A]. This suggests that slowing down perfusion rate during drug delivery did not affect OT content in $\mathrm{BNST}_{\mathrm{dl}}$ microdialysates. There was a significant main treatment effect in rats perfused with As2B $\left[F_{(2.260,29.38)}=6.921, P=0.0025\right]$. Post-hoc analysis has shown significantly increased OT content in the first sample collected after drug infusion $(30 \mathrm{~min}, P<$ 0.05 , Figure 2B) in comparison to pre-treatment OT content (Bonferroni's multiple comparisons). Although there was a significant main effect of Ucn3 treatment $\left[F_{(2.383,14.30)}=3.561\right.$, $P=0.0493]$, Bonferroni's multiple comparisons test did not show any differences between OT content at baseline and posttreatment microdialysates at any given time point. Application of $\mathrm{CRF}$ alone did not have any main treatment effect on OT content in microdialysates $\left[F_{(3.048,24.39)}=2.051, P=0.13\right]$. Combination of CRF and As2B also did not affect OT content in $\mathrm{BNST}_{\mathrm{dl}}$ microdialysates $\left[F_{(1.948,11.69)}=2.082, P=0.17\right]$. Similarly, coapplication of As2B with CRFR1 antagonist, NBI 35965, did not influence OT content in microdialysates $\left[F_{(2.700,13.50)}=0.1188\right.$, $P=0.93]$. Finally, treatment with CRF and NBI 35965 did not have any main effects on OT release $\left[F_{(3.123,21.86)}=0.5968, P=\right.$ 0.63 ], Table 1 .

To further exclude the possibility that the slower perfusion rate during drugs delivery $(1 \mu \mathrm{l} / \mathrm{min}$ for $15 \mathrm{~min})$ might have altered OT content in BNST $\mathrm{dl}$ microdialysates (independently of treatment), we have performed additional analysis in control rats (perfused with ACSF only). Here, we have compared OT levels in baseline microdialysates (mean of three baseline values) with OT levels in microdialysates collected during slower perfusion rate. The analysis showed no difference in OT content between the microdialysates collected before and after slowing down of perfusion rate $(P=0.98, n=19$, paired $t$-test $)$.

\section{Percentage Change of OT Content in BNST $_{\text {dl }}$ Microdialysates Following CRFR Modulation-Between Groups Analysis}

OT content was expressed as a percent change from baseline based on the average of three baseline values (100\%) for each rat. With post-hoc analysis, all treatment groups (including ACSF) were compared with each other in their respective time-points after a drug delivery. Comparing percentage changes in OT content in $\mathrm{BNST}_{\mathrm{dl}}$ microdialysates across all (7) treatment groups with two-way repeated measures ANOVA revealed a significant main effect of TREATMENT $\left[F_{(6,63)}=3.315, P=0.0067\right]$, and a significant effect of TIME $\left[F_{(5,315)}=2.417, P=0.0359\right]$, as well as significant interaction between TIME and TREATMENT $\left[F_{(30,315)}=1.549, P=0.0367\right]$.

Post-hoc analysis with Bonferroni's multiple comparison test revealed that infusion of CRFR2 agonist (Ucn3) did not affect OT release in the $\mathrm{BNST}_{\mathrm{dl}}$ at any time point in comparison to any other treatment group $(P>0.05$, Figure 3$)$. In contrast, infusion of CRFR2 antagonist alone (As2B) caused a significant increase in OT release measured at $30 \mathrm{~min}$ (first sample collected after the drug delivery) in comparison to the vehicle (ACSF) $(P<0.01$, Figure 3) and CRF-treated groups $(P<0.05)$. The effect of As2B was significantly reduced when As2B was coinfused with $\mathrm{CRF}(P<0.01$ in comparison to As2B alone). The effect of As2B was also significantly reduced when As2B was co-infused with CRFR1 antagonist, NBI $35965(P<$ 0.05 in comparison to As2B alone, Figure 4). In addition, As2B produced a delayed increase in OT content in $\mathrm{BNST}_{\mathrm{dl}}$ microdialysate $90 \mathrm{~min}$ after the drug infusion $(P<0.05$ in comparison to ACSF-treated group), which was not affected by local application of CRFR1 antagonist, NBI 35965, or CRF $(P>$ 0.05) (Figure 4).

Although application of CRF alone did not have any effect immediately after the drug infusion $(30 \mathrm{~min}, P>0.05$ in 

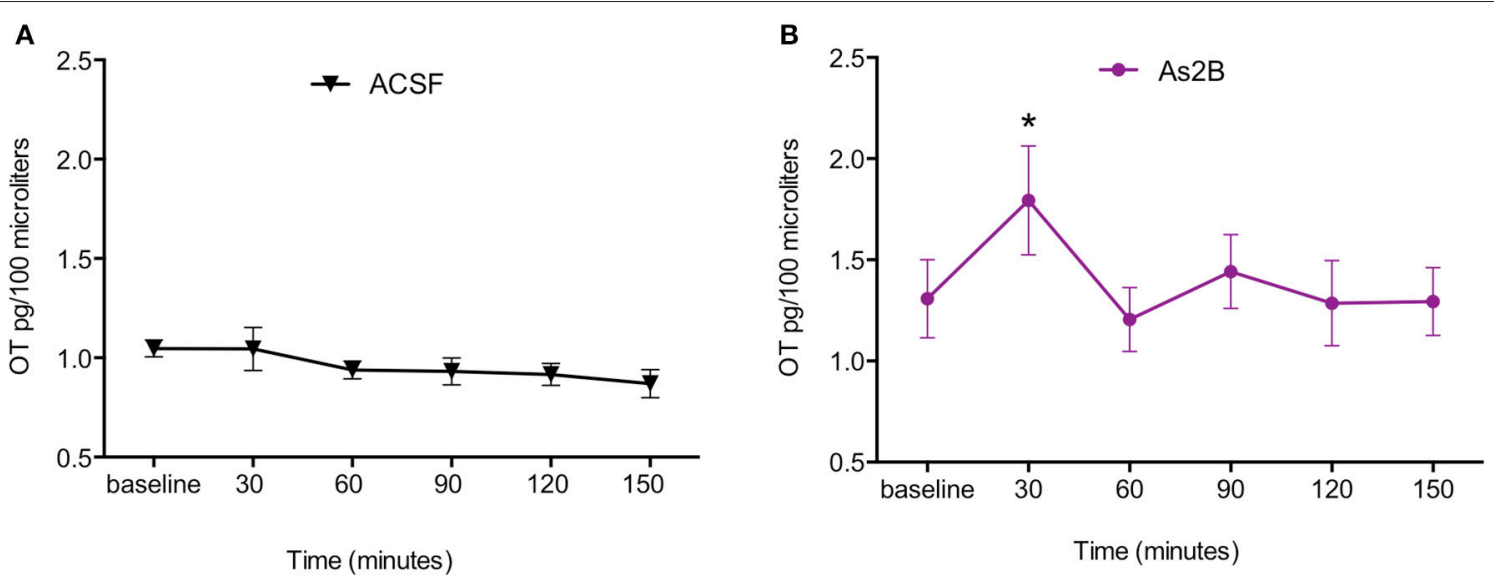

FIGURE 2 | CRFR2 blockade increases OT content in BNST ${ }_{d l}$ microdialysates. OT content in BNST dll microdialysates is expressed as MEAN \pm SEM of OT (pg) in $100 \mu \mathrm{l}$ microdialysis samples for ACSF (A) and As2B (B) treated groups. Baseline samples were collected in 30 min intervals before a drug delivery. (A) Perfusion of ACSF alone did not affect OT content in BNST dl microdialysates. (B) There was a significant main treatment effect in rats perfused with As2B (one-way ANOVA), and post-hoc analysis showed significantly increased OT content in the first sample collected after drug infusion ( $\left.30 \mathrm{~min},{ }^{*} P<0.05\right)$ in comparison to pre-treatment OT content (Bonferroni's multiple comparisons).

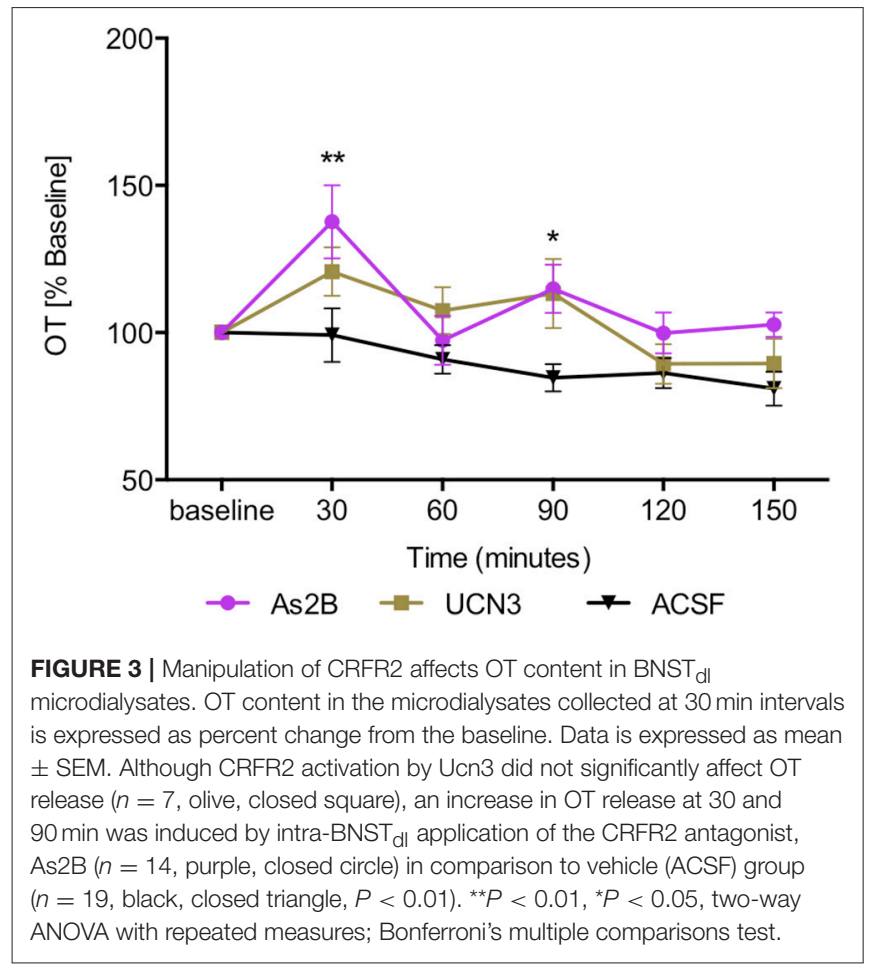

comparison to ACSF-treated rats), it induced a significant delayed increase in OT content in $\mathrm{BNST}_{\mathrm{dl}}$ microdialysate at $90 \mathrm{~min}$ (Figure 5), in comparison to the control (ACSF) group $(P<0.001)$. Interestingly, the delayed stimulatory effect of CRF on OT release was blocked by co-infusion with As2B $(P<0.01)$ (Figure 5), but not CRFR1 antagonist, NBI $35965(P>0.05)$ (Figure 5). This suggests that the delayed stimulatory effect of CRF on OT release in the $\mathrm{BNST}_{\mathrm{dl}}$ is mediated by local CRF2, but not CRF1 receptors.
None of the treatments affected OT content in $\mathrm{BNST}_{\mathrm{dl}}$ microdialysates at 60,120, and 150-min after the drug infusions $(P>0.05$, Figures 3-5).

\section{OT Content in BNST dl $_{\text {}}$ Microdialysates - Technical Considerations Microdialysis Membrane Cut-Off and OT Content in BNST $_{\text {dl }}$ Microdialysates}

We have compared baseline OT levels in rats implanted with Brainlink concentric probes $(n=9)$ and rats implanted with $\mathrm{U}$ shape probes $(n=61)$ and found a statistical difference (Brainlink $1.25 \mathrm{pg} \pm 0.05$, and U-shape $1.01 \mathrm{pg} \pm 0.04, P=0.0013$, unpaired $t$-test). This is most likely due to a higher cut-off of microdialysis membrane in Brainlink probes in comparison to $\mathrm{U}$ shape probes (50 vs. $18 \mathrm{kDa}$ ). We used percentage changes of OT content (calculated as a change from the baseline value for each rat) that allowed comparisons between treatment groups using two-way repeated measures ANOVA, hence higher absolute OT content in $\mathrm{BNST}_{\mathrm{dl}}$ microdialysates collected with Brainlink probes should not affect the results. However, to ensure that our major findings are not compromised by the data collected from rats implanted with Brainlink probes (As2B+CRF $n=6$ and ACSF $n=3$ ), we have removed the subjects from data analysis. Notably, the exclusion did not affect our main findings. Here, two-way repeated measures ANOVA of all six treatment groups (ACSF, Ucn3, As2B, CRF, As2B + NBI 35965, CRF + NBI 35965) revealed a significant main effect of TREATMENT $\left[F_{(4,47)}=\right.$ 3.630, $P=0.0117]$, and a significant main effect of TIME $\left[F_{(5,235)}\right.$ $=2.960, P=0.0130]$, but not a significant interaction between TIME and TREATMENT $\left[F_{(20,235)}=1.589, P=0.0562\right]$. Posthoc analysis with Bonferroni's multiple comparison test revealed that infusion of Ucn3 did not affect OT release in the $\mathrm{BNST}_{\mathrm{dl}}(P$ $>0.05$ ), whereas infusion of As2B caused a significant increase in OT release measured at $30 \mathrm{~min}$ in comparison to vehicle (ACSF) 


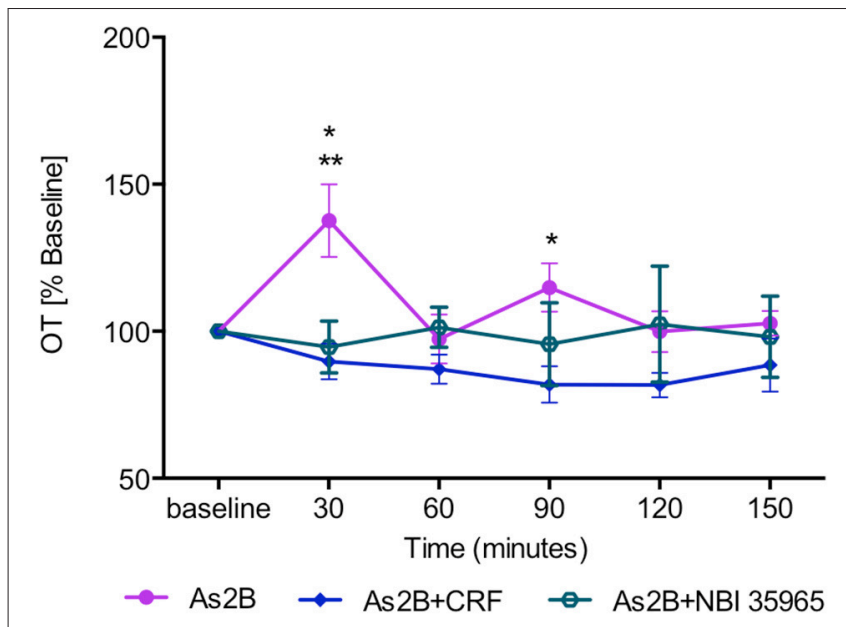

FIGURE 4 | The effect of CRFR2 antagonist (As2B) on OT content in BNST $d$ l microdialysates is modulated by CRFR1 manipulation. The effect of As2B on OT release at 30 min was occluded by intra-BNST $d$ application of CRFR1 antagonist NBI 35965 ( $n=6$, teal, open circle, $P<0.05)$ as well as application of $\operatorname{CRF}(n=7$, blue diamond, $P<0.01)$. The delayed stimulatory effect of As2B at 90 min was not affected by CRF or NBI 35965 application $(P>0.05)$. ${ }^{\star \star} P<0.01$, ${ }^{\star} P<0.05$, two-way ANOVA with repeated measures.

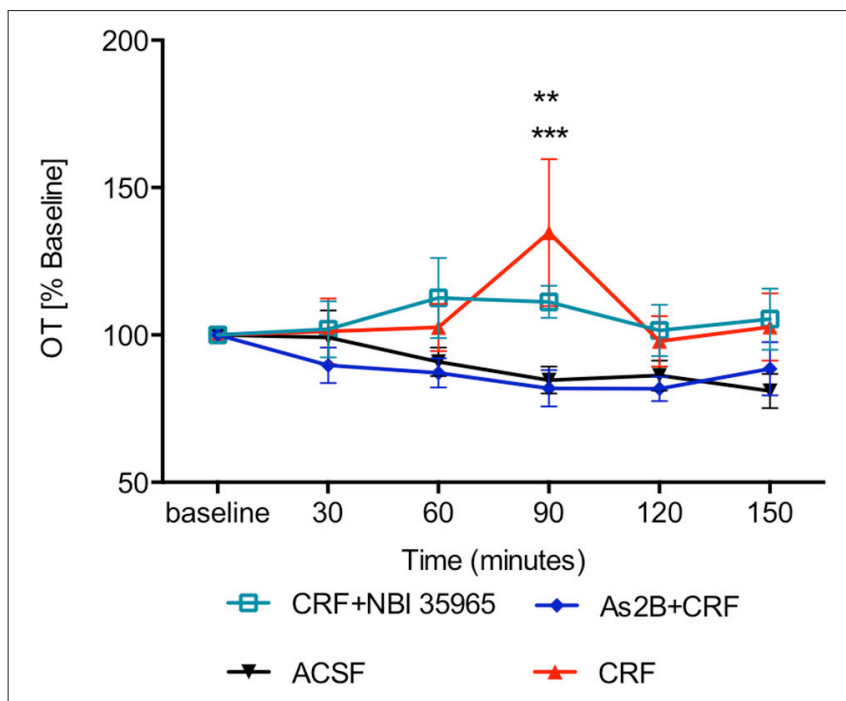

FIGURE 5 | OT content in BNST $\mathrm{Cl}_{\mathrm{dl}}$ microdialysates is modulated by CRF. CRF caused a significant increase in OT release at $90 \mathrm{~min}(n=9$, red triangle, $P<$ 0.001 in comparison to ACSF group). CRFR1 blockade by NBI 35965 did not significantly affect the effect of CRF on OT release $(n=8$, cyan, open square, $P>0.05)$. However, blocking CRFR2 with As2B abolished the effect of CRF on OT release $(n=7$, blue diamond, $P<0.01)$. ${ }^{\star \star \star} P<0.001$, ${ }^{\star \star} P<0.01$ two-way ANOVA with repeated measures.

$(P<0.01)$ and CRF-treated group $(P<0.05)$. The effect of As2B was significantly reduced when As2B was co-infused with CRFR1 antagonist $(P<0.05)$. In addition, As2B also produced a delayed increase in OT content in $\mathrm{BNST}_{\mathrm{dl}}$ microdialysate at $90 \mathrm{~min}(P$ $<0.05$ in comparison to the ACSF-treated group), which was not affected by local application of the CRFR1 antagonist, NBI
$35965(P<0.05)$. Although application of CRF alone did not have any effect immediately after the drug infusion (30 min, $P>$ 0.05 in comparison to ACSF-treated rats), CRF induced a delayed significant increase in OT content in $\mathrm{BNST}_{\mathrm{dl}}$ microdialysate at $90 \mathrm{~min}$ in comparison to the control (ACSF) group $(P<0.001)$. The delayed stimulatory effect of CRF on OT release was not affected by co-infusion of CRFR1 antagonist $(P>0.05)$.

\section{Type of Anesthesia During Surgery and OT Content in BNST $_{\text {dl }}$ Microdialysates}

Here, we have compared baseline OT content in $\mathrm{BNST}_{\mathrm{dl}}$ microdialysates between rats anesthetized during surgery with isoflurane (1.13 pg $\pm 0.06, n=51)$ or ketamine/dexdormitor mixture (1.31 pg $\pm 0.06, n=19)$ and found no statistical difference between the two groups of animals $(P=0.15$, unpaired $t$-test). To determine whether type of anesthesia during surgery could interfere with treatment and therefore affect OT content in $\mathrm{BNST}_{\mathrm{dl}}$ microdialysates, we have performed two-way ANOVA for the As2B-treated group with factors TREATMENT (predrug, post-drug) and ANESTHESIA (isoflurane or cocktail of ketamine/dexdormitor). We chose the As2B group because of the significant effect of As2B on OT content in $B_{\mathrm{NST}}$ microdialysates (see results above) and because this group contained equal numbers of rats anesthetized with isoflurane $(n=7)$ and rats anesthetized with ketamine/dexdormitor $(n=$ 7) during surgery. We have noted a significant effect of As2B TREATMENT $\left[F_{(1,12)}=12.09, P=0.0046\right]$, but there was no significant effect of ANETHESIA $\left[F_{(1,12)}=0.2673, P=0.61\right]$, nor interaction between the TREATMENT and ANETHESIA $\left[F_{(1,12)}=0.8593, P=0.37\right]$.

\section{Peptide Retrodialysis and OT Content in the Microdialysates - ex Vivo Experiment}

To determine whether peptides used in the treatment groups (CRF, Ucn3, and As2B) could potentially interfere with the OT antibody used in the RIA, we have performed an ex vivo experiment in which $\mathrm{U}$-shape microdialysis probes were perfused with ACSF only ( $n=6$ samples collected), or with ACSF containing $\operatorname{CRF}(n=4)$, or $\operatorname{Ucn} 3(n=4)$, or As2B $(n=4)$ at the concentration and the flow rate as above. The samples were collected into Eppendorf tubes as above and sent for RIA analysis together with the samples collected from in vivo microdialysis. Samples obtained from CRF and As2B perfusion were not significantly different from samples perfused with ACSF only ( $P=0.58$ and $P=0.13$, respectively, unpaired $t$-test). However, samples perfused with Ucn3 had significantly higher levels of OT than samples perfused with ACSF only $(P=0.0488$, unpaired $t$-test), suggesting that $U \mathrm{cn} 3$ might potentially interact with the RIA, leading to false positive results. To ensure that this has not interfered with our major findings, we have excluded the Ucn3-treated group from the analysis. Notably, exclusion of the Ucn3 group did not affect our major findings in any significant way. Here, two-way repeated measures ANOVA of six treatment groups (ACSF, As2B, CRF, As2B + CRF, As2B + NBI 35965, CRF + NBI 35965) revealed a significant main effect of TREATMENT $\left[F_{(4,50)}=4.468, P=0.0036\right]$, no significant effect of TIME 
$\left[F_{(5,250)}=1.346, P=0.24\right]$, but a significant interaction between TIME and TREATMENT $\left[F_{(20,250)}=1.776, P=0.0236\right]$.

Post-hoc analysis with Bonferroni's multiple comparison test confirmed that infusion of As2B caused a significant increase in OT release measured at $30 \mathrm{~min}$ in comparison to the vehicle (ACSF) $(P<0.01)$ and CRF-treated groups $(P<0.05)$. The effect of As2B was significantly reduced when As2 B was co-infused with the CRFR1 antagonist $(P<0.05)$, or $\operatorname{CRF}(P<0.01)$. In addition, As2 $\mathrm{B}$ also produced a delayed increase in OT content in $\mathrm{BNST}_{\mathrm{dl}}$ microdialysate at $90 \mathrm{~min}(P<0.05$ in comparison to ACSFtreated group), which was not affected by application of CRFR1 antagonist $(P>0.05)$. Although application of CRF alone did not have any effect immediately after the drug infusion $(30 \mathrm{~min}, P>$ 0.05 in comparison to ACSF-treated rats), it induced a delayed significant increase in $\mathrm{OT}$ content in $\mathrm{BNST}_{\mathrm{dl}}$ microdialysate at $90 \mathrm{~min}$ in comparison to the control (ACSF) group $(P<0.001)$, which was significantly reduced by infusion of As2B $(P<0.01)$, but not CRFR1 antagonist $(P>0.05)$.

\section{DISCUSSION}

Using in vivo microdialysis in freely-moving male rats we demonstrate for the first time that OT release in the $\mathrm{BNST}_{\mathrm{dl}}$ is modulated by members of the CRF-peptide family and that CRFR1 and CRFR2 play distinct roles in this modulation. Our results show that blockade of CRFR2 with As2B caused an increase in OT content in $\mathrm{BNST}_{\mathrm{dl}}$ microdialysates. Analysis of percentage change of OT content between the treatment groups show that the stimulatory effect of AS2B depends on intact CRFR1 transmission, because the effect of As2B was abolished when CRFR1 were blocked at the same time. In addition, although CRF alone had no immediate effect on OT release, it had a delayed effect on OT content in $\mathrm{BNST}_{\mathrm{dl}}$ microdialysates, which was blocked by intra-BNST $\mathrm{dl}$ application of CRFR2 but not CRFR1 antagonist.

In contrast to widely expressed CRFR 1 in rat brain, expression patterns of CRFR2 are more distinct. For example, although CRFR2 mRNA has been found in many brain regions including posterior BNST, its mRNA expression is sparse in the BNST $_{\mathrm{dl}}$ or CeA (Chalmers et al., 1995; Van Pett et al., 2000). However, like CRFR1, which has been found at both pre- (Nie et al., 2009) and post-synaptic sites (Fu and Neugebauer, 2008), pre-synaptic CRFR2-mediated modulation of neuronal excitability has been demonstrated in the CeA (Fu and Neugebauer, 2008), LS and nucleus of the solitary tract (Lawrence et al., 2002). Therefore, the previous and current findings indicate that in the $\mathrm{BNST}_{\mathrm{dl}}$ CRFR2 localized on OT fibers modulate OT release via a pre-synaptic mechanism.

Our finding that selective activation of CRFR2 by Ucn3 did not have any effect on OT content in $\mathrm{BNST}_{\mathrm{dl}}$ microdialysates appears in contrast to previously reported findings in $\mathrm{NaC}$ in male prairie voles, where Ucn3 reduced release of OT. However, it should be noted that the decrease observed in the latter study was statistically significant when comparing OT content in two subsequent microdialysates (Bosch et al., 2016). In the current study, obtaining significant results of two-way ANOVA allowed us to compare all treatment groups to each other at their respective time points and the effect of Ucn3 was not significantly different in comparison to any other treatment group, including control (ACSF) group. In addition, in the previous study Ucn3 was delivered ICV via guide cannula and might have therefore imposed direct inhibitory effect on OT neurons in the hypothalamus. Indeed, excitatory drive onto OT neurons in vole PVN was significantly reduced after application of Ucn3 in hypothalamic slices from voles (Bosch et al., 2016). Ucn3-mediated inhibition of hypothalamic OT neurons has been also demonstrated in rat brain (Chu et al., 2013). Nonetheless, caution needs to be applied when interpreting current Ucn3 results because ex vivo experiment indicated that exogenous Ucn3 might potentially interact with the RIA used to measure OT. Thus, if Ucn 3 produces false positive results by interacting with the RIA, this might mask its potential inhibitory effect in vivo. One-way ANOVA showed an overall significant main effect of Ucn3 treatment on OT content in $\mathrm{BNST}_{\mathrm{dl}}$ microdialysates but multiple comparisons failed to show differences at any given time point after the drug delivery, which might further support the explanation. Based on these findings, we cannot draw a definitive conclusion about the lack of Ucn3 modulation of OT release in the $\mathrm{BNST}_{\mathrm{dl}}$. However, despite the technical limitations, exclusion of the Ucn3-treated rats did not affect our main significant findings, including the effects of As2B or CRF application on OT release in the $\mathrm{BNST}_{\mathrm{dl}}$.

The most significant finding of the current study showed that blockade of CRFR2 by As2B causes a significant increase in OT content in $\mathrm{BNST}_{\mathrm{dl}}$ microdialysates. This effect is consistent with previously reported results showing an increase in OT release in $\mathrm{NaC}$ after As2 B was delivered ICV in prairie voles (Bosch et al., 2016). However, in the former study the effect was observed with delay, whereas in the current study it was observed in the first microdialysate after As2B delivery via retrodialysis, suggesting involvement of local CRFR2 in the $\mathrm{BNST}_{\mathrm{dl}}$. Taken together these results suggest that CRFR2 impose inhibitory effect on OT release in the $\mathrm{BNST}_{\mathrm{dl}}$, which is unmasked when CRFR2 are blocked, resulting in immediate increase in OT content. Furthermore, the effect of As2B on percentage change of OT content was abolished when combined with CRFR1 antagonist (NBI 35965), suggesting that intact CRFR1 transmission is also required for the increase in OT release.

Like Ucn3, CRF alone did not have any immediate effect on OT release. Therefore, we hypothesized that CRF has a stimulatory effect on OT release via CRFR1, but this is masked by the inhibitory influence of CRFR2. To test this hypothesis, we have applied exogenous CRF while blocking CRFR2 with As2B. Surprisingly, the stimulatory effect of As2B was occluded by application of exogenous CRF. The fact that either the CRFR1 antagonist or CRF blocked the effect of As2B seems puzzling, considering that CRFR1 is a primary receptor for CRF (Hauger et al., 2003a). Since neither Ucn3 nor CRF alone had an immediate effect on OT release, it may be that other members of the CRF peptide family modulate OT release via CRF2R and CRFR1. Ucn2 and Ucn1 are plausible candidates as both Ucn1 and CRF are considered endogenous ligands of CRFR1, whereas Ucn2 and Ucn3 are considered selective CRFR2 ligands 
(Hauger et al., 2003a). Although Ucn3 is more selective toward CRFR2 than Ucn2 (Ucn2 also binds to the CRF binding protein), the latter has higher affinity toward CRFR2 than Ucn3 (0.25 vs. $14 \mathrm{nM}$, respectively) (Henckens et al., 2016). Hence, Ucn2 is a plausible mediator of tonic activity of CRFR2 in the $\mathrm{BNST}_{\mathrm{dl}}$.

Furthermore, the Edinger-Westphal nucleus, which contains neurons producing $U \mathrm{cn} 1$, has been shown to send dense efferent projections to the oval nucleus of the $\mathrm{BNST}_{\mathrm{dl}}$ (Dos Santos Junior et al., 2015), although another study did not detect Ucn1 immunoreactive processes in rat BNST (Kozicz et al., 1998). Although seemingly contradictory, it is important to note that the latter study used colchicine injections to visualize Ucn1 peptide primarily at the level of cell bodies in the Edinger-Westphal nucleus, which has inevitably prevented Ucn1 immunoreactivity at the level of axons and processes, e.g., in the BNST. Although distinct roles of CRF vs. Ucn1 neurotransmission are not wellunderstood, differential responses of CRF and Ucn1 systems to acute pain stress have been demonstrated in rat brain (Rouwette et al., 2011). Interestingly, central administration of Ucn1 has been shown to inhibit hyperosmolality-induced vasopressin release in rat SON but CRF demonstrated no effect (Kakiya et al., 1998). In addition, the number of Ucn1 neurons co-expressing FosB in Edinger-Westphal nucleus has been significantly increased in mice genetically predisposed to stress effects and exposed to chronic stress (Farkas et al., 2017). In fact, Ucn1/CRFR2 signaling in the BNST was postulated to play the role in long-term adaptation to and recovery from stress (Kormos and Gaszner, 2013). Strikingly, Ucn1 has higher affinity to CRFR1 than CRF itself (0.17 vs. $1.6 \mathrm{nM}$, respectively) (Henckens et al., 2016). Furthermore, although it has higher affinity toward CRFR1 than CRFR2 $(0.86 \mathrm{nM})$, it can efficiently bind to both CRFR receptors (Henckens et al., 2016). Thus, Ucn1 rather than CRF might act through CRFR to modulate OT release. All these findings support potentially distinct contributions of CRF vs. Urocortins to the regulation of OT release in the $\mathrm{BNST}_{\mathrm{dl}}$. Finally, some studies suggested that CRF, Urocortins, and As2B could bind to distinct domains of CRFR2, and therefore affect its transmission differently (Perrin et al., 2003).

As2B also demonstrated a delayed effect on change in OT content, which was affected neither by CRFR1 blockade nor application of CRF. Since the drugs were delivered via retrodialysis, these results suggest that the delayed effect of As2B at $90 \mathrm{~min}$ is not mediated by local CRFR in the $\mathrm{BNST}_{\mathrm{dl}}$ but rather by a feedback mechanism. In fact, As2B-induced immediate increase in OT release $(30 \mathrm{~min})$ might activate $\mathrm{BNST}_{\mathrm{dl}}$ neurons, as OT was shown to excite BNST neurons before (Ingram et al., 1990). From there, PVN-projecting $B_{N S T}$ dl neurons that innervate OT cells (Dabrowska et al., 2016) might affect their activity and hence induce delayed terminal OT release in the $\mathrm{BNST}_{\mathrm{dl}}$. The delayed stimulatory effect of CRF on OT content in $\mathrm{BNST}_{\mathrm{dl}}$ microdialysates was observed at the same time-point as for As2B alone ( $90 \mathrm{~min}$ ), which suggests that both compounds might act via a common mechanism. Although this suggests that the delayed stimulatory effect of CRF on OT release in the $\mathrm{BNST}_{\mathrm{dl}}$ is primarily mediated by CRFR2, and not CRF1R, high variability observed in the CRF group have inevitably prevented a significant difference, when comparing CRF to CRF co-applied with NBI 35965. Based on current results we propose the following working model of the regulation of OT release in the $\mathrm{BNST}_{\mathrm{dl}}$. OT release is maintained at a low level by tonic activation of presynaptic CRFR2. Therefore, adding exogenous Ucn3 could not suppress OT release but blockade of CRFR2 immediately increases OT content in $\mathrm{BNST}_{\mathrm{dl}}$ microdialysates. This effect is also CRFR1-dependent, but not mediated by CRF itself, suggesting the involvement of other members of the CRF peptide family, including Ucn1 acting via CRFR1.

Modulation of OT release most likely also involves intrinsic inhibitory networks as well as extrinsic excitatory innervation of the BNST. CRFR have been shown to display a wide range of modulatory functions in the BNST. CRFR1 activation was shown to potentiate glutamatergic transmission, demonstrated as increased frequency of spontaneous excitatory synaptic currents, suggesting pre-synaptic locus of the CRFR1 action (Kash et al., 2008; Silberman et al., 2013). In contrast, in ventral BNST, CRFR1 activation enhanced postsynaptic responses to GABA, promoting inhibition (Kash and Winder, 2006). Although postsynaptic CRFR2 have been found in posterior BNST (Henckens et al., 2016), our previous electron microscopy study supports pre-synaptic localization of CRFR2 in the BNST $\mathrm{dl}_{\mathrm{dl}}$ (Dabrowska et al., 2011). In the CeA, blockade of CRFR2 by As2B facilitated synaptic transmission through presynaptic inhibition of GABAergic transmission (disinhibition), whereas blocking CRFR1 had contrasting effect (Fu and Neugebauer, 2008).

CRFR ligands display unique expression patterns throughout the brain but their subcellular locations (e.g., axon vs. dendrite) still remain elusive. In the BNST, the majority of CRFRlabeling (not distinguished between CRFR1 and CRFR2) was observed on the plasma membrane or within dendritic profiles, indicating both post- and/or presynaptic localization (Jaferi and Pickel, 2009). CRFR-labeled axon terminals were shown to form asymmetric, excitatory-type synapses with dendritic spines (Jaferi et al., 2009). In addition, CRFR were also found in dendritic profiles receiving asymmetric, excitatory-type synapses. Presence of the CRFR within some of the excitatory-type terminals that are presynaptic to dendrites expressing CRFR suggests that the CRFR can also affect the activity of local BNST neurons through presynaptic mechanisms (Jaferi et al., 2009). This is consistent with our previous study showing CRFR2-immunoreactive axon terminals and dendrites forming asymmetric, excitatory synapses with dendrites or dendritic spines (Dabrowska et al., 2011).

Therefore, in the BNST, CRFR-immunoreactive axons appear primarily glutamatergic, whereas CRFR-immunoreactive dendrites are primarily GABA-ergic. Only small fraction of CRFR dendrites and terminals in the BNST also contain CRF (Jaferi and Pickel, 2009). As BNST neurons are primarily GABA-ergic (Sun and Cassell, 1993; Dabrowska et al., 2013), glutamatergic CRFR-expressing terminals in the BNST are extrinsic in origin. It is important to note that BNST-projecting hypothalamic OT neurons also express glutamatergic markers (Dabrowska et al., 2011, 2013), suggesting that CRFR2-expressing terminals might co-release both OT and glutamate in the BNST $\mathrm{dl}_{\mathrm{dl}}$. Based on these findings, CRFR2 on excitatory OT fibers might also interact with CRFR1 located on dendrites of local GABA-ergic neurons. Hence, the CRF-mediated delayed OT release could be the result of a suppression of local inhibitory networks via CRFR1. On the other hand, glutamate co-released with OT could also increase 
excitation of local GABA-ergic networks, facilitating long-term effects on OT release.

In addition, both CRFR1 and CRFR2 exert their effects also via changes in intracellular signaling pathways, including extracellular signal-regulated kinase (ERK) and mitogenactivated protein kinase (MAPK), as well as regulation of transcription of downstream target genes. Finally, after CRFR binding, G protein-coupled receptor kinases rapidly phosphorylate the receptors, leading to CRFR internalization, and changes in receptor signaling pathways (Henckens et al., 2016). Delayed changes in gene transcription as well as CRFR trafficking could also lead to the delayed effects of CRFR on OT release.

There are several technical limitations in the current study that need to be addressed. However, extensive statistical tests have been performed to exclude a possibility that these limitations might have interfered with our major findings. For example, slower flow rate during treatment might have resulted in higher OT content in the first microdialysate following drug application. However, we have tested the potential effect the slower rate (for $15 \mathrm{~min}$ ) might have in 19 control rats infused with ACSF only, and we have not observed any significant effect on OT content. All drugs (including ACSF) were delivered in an identical manner in all treatment groups. In addition, all samples were compared to each other at their respective time points after drug delivery. In fact, As2B is the only group that shows significant increase of $\mathrm{OT}$ content in $\mathrm{BNST}_{\mathrm{dl}}$ microdialysate at $30 \mathrm{~min}$ (in comparison to both ACSF and CRF-treated group), whereas CRF-mediated increase has been observed at $90 \mathrm{~min}$ after drug administration. Therefore, our major findings that As2B and CRF modulate OT release in the $\mathrm{BNST}_{\mathrm{dl}}$ are due to their pharmacological effects and are not compromised by the technical limitations. However, it has been demonstrated that microglia and astrocytes express both CRFR1 and CRFR2. If astrocytes and microglia are cellular targets of CRF, gliosis and neuroinflammation around the microdialysis probe might have also affected our results and OT content in $\mathrm{BNST}_{\mathrm{dl}}$ microdialysates (Stevens et al., 2003).

In addition, our ex vivo experiment has shown that Ucn3 might interfere with the RIA used to measure OT content. However, we have re-analyzed the results after exclusion of Ucn3treated group and it did not affect significant effects of As2B and CRF on OT release. Similarly, even though a probe with a higher cut-off was used for a small group of rats, exclusion of the group from the data analysis also did not change any major findings referenced above.

In order to determine whether the effects of CRFR modulation of OT release are specific to the $\mathrm{BNST}_{\mathrm{dl}}$, microdialysis samples from rats with off-target cannula placements should also have been analyzed in RIA. Misplacement of the cannulas could be confirmed in only 4 of the 9 excluded rats, the remaining brains showed good cannula trajectory toward the $\mathrm{BNST}_{\mathrm{dl}}$, but the location of the tip of the probe could not be unequivocally confirmed. Therefore, these samples could not be used as confirmed negative controls.

CRFR ligands used in the study are competitive ligands. As they compete for binding on the same receptor, this might have masked an antagonist effect if an agonist reached the receptor first. However, in regard of co-administration of As2B with CRF, the affinity of As2B for the CRFR2 is very high ( $1 \mathrm{nM}$ range), whereas the affinity of CRF to CRFR2 is substantially lower (42 nM) (Henckens et al., 2016). Although there still could be differences in diffusion rates between the As2B and CRF from the ACSF to extracellular space, this is unlikely as they are used at the same concentration $(10 \mu \mathrm{M})$ and both peptides have similar molecular weights $(4,757.52$ and $4,041.69 \mathrm{~g} / \mathrm{mol}$, CRF and As2B, respectively). As As2B has much higher affinity and a smaller molecular size, it would presumably arrive at CRFR2 site faster and bind more efficiently than the agonist, CRF. In regard to co-application of CRF and NBI 35965, the latter is a non-peptide CRFR1 antagonist and therefore has a considerably smaller molecular weight of 437.79 grams/mol. Both CRF and NBI 35965 were used in the same concentration of $10 \mu \mathrm{M}$ but because of the smaller size, NBI 35965 would presumably diffuse and reach CRFR1 site faster than CRF. However, caution needs to be applied as although NBI 35965 has much higher affinity to CRFR1 (4 $\mathrm{nM}$ range) vs. CRFR2 (>10,000 nM), it has a lower affinity than a CRF for CRFR1 (1.6 nM) (Henckens et al., 2016). Co-application of NBI 35965 and As2B should not be an issue, because these are selective antagonists of CRFR1 and CRFR2, respectively.

Stress activation of the HPA axis and the anxiogenic and depressive-like effects of CRF are primarily mediated by activation of CRFR1 (Sahuque et al., 2006; Kehne and Cain, 2010), (but see Coste et al., 2000). However, there are many conflicting findings on the behavioral effects of CRFR2 activation (Valdez et al., 2003; Risbrough et al., 2004), gene deletion (Coste et al., 2000; Kishimoto et al., 2000), or blockade (Takahashi et al., 2001). In fact, growing evidence suggests that the role of CRF peptide family members in stress and anxiety is largely brain-region specific (Janssen and Kozicz, 2013; Henckens et al., 2016). For example, lack of CRFR1 on glutamatergic neurons in the amygdala reduces anxiety, whereas selective deletion of CRFR1 in midbrain dopaminergic neurons increases anxietylike behavior (Refojo et al., 2011). The behavioral effects of CRFR2 in the BNST have also been inconsistent (Sahuque et al., 2006; Lebow et al., 2012; Elharrar et al., 2013). In addition, the BNST is a heterogeneous structure containing sub-nuclei that express variety of neuropeptides, and activation of different sub-nuclei often leads to contrasting physiological and behavioral effects (Daniel and Rainnie, 2016). Therefore, the role of CRFR1 and CRFR2 should also be investigated in BNST sub-nuclei dependent manner. Based on our previous (Dabrowska et al., 2011) and current findings we propose that CRF receptors in the $\mathrm{BNST}_{\mathrm{dl}}$ may function to modulate stress and anxiety-like behavior via an interaction with the OT system. We have recently shown that OT neurotransmission in the $\mathrm{BNST}_{\mathrm{dl}}$ facilitates cued fear learning (Moaddab and Dabrowska, 2017). Therefore, CRFR might modulate fear and anxiety responses at least partially via modulation of OT release in the $\mathrm{BNST}_{\mathrm{dl}}$. Our current findings imply that the interaction between CRF receptors and OT release might affect a whole array of responses, including sensitivity to stressors, fear and anxiety, as well as depressive-like behaviors (Coste et al., 2000; Kishimoto et al., 
2000). Future studies will focus on investigating the role of CRFpeptide family members in stress-induced OT release in the $\mathrm{BNST}_{\mathrm{dl}}$.

\section{AUTHOR CONTRIBUTIONS}

JD designed the study; DM acquired data; DM and JD analyzed and interpreted data, and wrote the manuscript.

\section{REFERENCES}

Arima, H., and Aguilera, G. (2000). Vasopressin and oxytocin neurones of hypothalamic supraoptic and paraventricular nuclei co-express mRNA for Type-1 and Type-2 corticotropin-releasing hormone receptors. J. Neuroendocrinol. 12, 833-842. doi: 10.1046/j.1365-2826.2000.00528.x

Bosch, O. J., Dabrowska, J., Modi, M. E., Johnson, Z. V., Keebaugh, A. C., Barrett, C. E., et al. (2016). Oxytocin in the nucleus accumbens shell reverses CRFR2-evoked passive stress-coping after partner loss in monogamous male prairie voles. Psychoneuroendocrinology 64, 66-78. doi: 10.1016/j.psyneuen.2015.11.011

Bosch, O. J., and Young, L. J. (2017). Oxytocin and social relationships: from attachment to bond disruption. Curr. Top. Behav. Neurosci. doi: 10.1007/7854_2017_10. [Epub ahead of print].

Bruhn, T. O., Sutton, S. W., Plotsky, P. M., and Vale, W. W. (1986). Central administration of corticotropin-releasing factor modulates oxytocin secretion in the rat. Endocrinology 119, 1558-1563. doi: 10.1210/endo-119-4-1558

Chalmers, D. T., Lovenberg, T. W., and De Souza, E. B. (1995). Localization of novel corticotropin-releasing factor receptor (CRF2) mRNA expression to specific subcortical nuclei in rat brain: comparison with CRF1 receptor mRNA expression. J. Neurosci. 15, 6340-6350.

Chu, C. P., Jin, W. Z., Bing, Y. H., Jin, Q. H., Kannan, H., and Qiu, D. L. (2013). Effects of stresscopin on rat hypothalamic paraventricular nucleus neurons in vitro. PLoS ONE 8:e53863. doi: 10.1371/journal.pone.0053863

Coste, S. C., Kesterson, R. A., Heldwein, K. A., Stevens, S. L., Heard, A. D., Hollis, J. H., et al. (2000). Abnormal adaptations to stress and impaired cardiovascular function in mice lacking corticotropin-releasing hormone receptor-2. Nat. Genet. 24, 403-409. doi: 10.1038/74255

Dabrowska, J., Hazra, R., Ahern, T. H., Guo, J. D., McDonald, A. J., Mascagni, F., et al. (2011). Neuroanatomical evidence for reciprocal regulation of the corticotrophin-releasing factor and oxytocin systems in the hypothalamus and the bed nucleus of the stria terminalis of the rat: implications for balancing stress and affect. Psychoneuroendocrinology 36, 1312-1326. doi: 10.1016/j.psyneuen.2011.03.003

Dabrowska, J., Hazra, R., Guo, J. D., Dewitt, S., and Rainnie, D. G. (2013). Central CRF neurons are not created equal: phenotypic differences in CRF-containing neurons of the rat paraventricular hypothalamus and the bed nucleus of the stria terminalis. Front. Neurosci. 7:156. doi: 10.3389/fnins.2013.00156

Dabrowska, J., Martinon, D., Moaddab, M., and Rainnie, D. G. (2016). Targeting corticotropin-releasing factor projections from the oval nucleus of the bed nucleus of the stria terminalis using cell-type specific neuronal tracing studies in mouse and rat brain. J. Neuroendocrinol. 28. doi: 10.1111/jne.12442

Daniel, S. E., and Rainnie, D. G. (2016). Stress modulation of opposing circuits in the bed nucleus of the stria terminalis. Neuropsychopharmacology 41, 103-125. doi: $10.1038 /$ npp. 2015.178

Dos Santos Junior, E. D., Da Silva, A. V., Da Silva, K. R., Haemmerle, C. A., Batagello, D. S., Da Silva, J. M., et al. (2015). The centrally projecting EdingerWestphal nucleus-I: efferents in the rat brain. J. Chem. Neuroanat. 68, 22-38. doi: 10.1016/j.jchemneu.2015.07.002

Ebner, K., Bosch, O. J., Kromer, S. A., Singewald, N., and Neumann, I. D. (2005). Release of oxytocin in the rat central amygdala modulates stress-coping behavior and the release of excitatory amino acids. Neuropsychopharmacology 30, 223-230. doi: 10.1038/sj.npp.1300607

Elharrar, E., Warhaftig, G., Issler, O., Sztainberg, Y., Dikshtein, Y., Zahut, R., et al. (2013). Overexpression of corticotropin-releasing factor receptor type 2

\section{ACKNOWLEDGMENTS}

We would like to thank Mitchell Beales for helpful comments and edits of the manuscript. This work was supported by grants from the National Institute of Mental Health R00 MH096746 and R01 MH113007 DePaul-RFUMS seed research grant to JD, as well as start-up funds from the Chicago Medical School, Rosalind Franklin University of Medicine Science to JD.

in the bed nucleus of stria terminalis improves posttraumatic stress disorderlike symptoms in a model of incubation of fear. Biol. Psychiatry 74, 827-836. doi: 10.1016/j.biopsych.2013.05.039

Farkas, J., Kovacs, L. A., Gaspar, L., Nafz, A., Gaszner, T., Ujvari, B., et al. (2017). Construct and face validity of a new model for the three-hit theory of depression using PACAP mutant mice on CD1 background. Neuroscience 354, 11-29. doi: 10.1016/j.neuroscience.2017.04.019

Fu, Y., and Neugebauer, V. (2008). Differential mechanisms of CRF1 and CRF2 receptor functions in the amygdala in pain-related synaptic facilitation and behavior. J. Neurosci. 28, 3861-3876. doi: 10.1523/JNEUROSCI.0227-08.2008

Hascup, E. R., Bjerken, S., Hascup, K. N., Pomerleau, F., Huettl, P., Stromberg, I., et al. (2009). Histological studies of the effects of chronic implantation of ceramic-based microelectrode arrays and microdialysis probes in rat prefrontal cortex. Brain Res. 1291, 12-20. doi: 10.1016/j.brainres.2009.06.084

Hauger, R. L., Grigoriadis, D. E., Dallman, M. F., Plotsky, P. M., Vale, W. W., and Dautzenberg, F. M. (2003a). International union of pharmacology. XXXVI. Current status of the nomenclature for receptors for corticotropin-releasing factor and their ligands. Pharmacol. Rev. 55, 21-26. doi: 10.1124/pr.55.1.3

Hauger, R. L., Olivares-Reyes, J. A., Braun, S., Catt, K. J., and Dautzenberg, F. M. (2003b). Mediation of corticotropin releasing factor type 1 receptor phosphorylation and desensitization by protein kinase C: a possible role in stress adaptation. J. Pharmacol. Exp. Ther. 306, 794-803. doi: 10.1124/jpet.103.050088

Henckens, M. J., Deussing, J. M., and Chen, A. (2016). Region-specific roles of the corticotropin-releasing factor-urocortin system in stress. Nat. Rev. Neurosci. 17, 636-651. doi: 10.1038/nrn.2016.94

Ingram, C. D., Cutler, K. L., and Wakerley, J. B. (1990). Oxytocin excites neurones in the bed nucleus of the stria terminalis of the lactating rat in vitro. Brain Res. 527, 167-170. doi: 10.1016/0006-8993(90)91078-U

Jaferi, A., Lane, D. A., and Pickel, V. M. (2009). Subcellular plasticity of the corticotropin-releasing factor receptor in dendrites of the mouse bed nucleus of the stria terminalis following chronic opiate exposure. Neuroscience 163, 143-154. doi: 10.1016/j.neuroscience.2009.06.029

Jaferi, A., and Pickel, V. M. (2009). Mu-opioid and corticotropin-releasing-factor receptors show largely postsynaptic co-expression, and separate presynaptic distributions, in the mouse central amygdala and bed nucleus of the stria terminalis. Neuroscience 159, 526-539. doi: 10.1016/j.neuroscience.2008.12.061

Jamieson, B. B., Nair, B. B., and Iremonger, K. J. (2017). Regulation of hypothalamic CRH neuron excitability by oxytocin. J. Neuroendocrinol. 29:e12532. doi: 10.1111/jne.12532

Janssen, D., and Kozicz, T. (2013). Is it really a matter of simple dualism? Corticotropin-releasing factor receptors in body and mental health. Front. Endocrinol. 4:28. doi: 10.3389/fendo.2013.00028

Ji, G., and Neugebauer, V. (2007). Differential effects of CRF1 and CRF2 receptor antagonists on pain-related sensitization of neurons in the central nucleus of the amygdala. J. Neurophysiol. 97, 3893-3904. doi: 10.1152/jn.00135.2007

Jurek, B., Slattery, D. A., Hiraoka, Y., Liu, Y., Nishimori, K., Aguilera, G., et al. (2015). Oxytocin regulates stress-induced Crf gene transcription through CREB-regulated transcription coactivator 3. J. Neurosci. 35, 12248-12260. doi: 10.1523/JNEUROSCI.1345-14.2015

Kakiya, S., Yokoi, H., Arima, H., Iwasaki, Y., Oki, Y., and Oiso, Y. (1998). Central administration of urocortin inhibits vasopressin release in conscious rats. Neurosci. Lett. 248, 144-146. doi: 10.1016/S0304-3940(98)00357-7

Kash, T. L., Nobis, W. P., Matthews, R. T., and Winder, D. G. (2008). Dopamine enhances fast excitatory synaptic transmission in the extended 
amygdala by a CRF-R1-dependent process. J. Neurosci. 28, 13856-13865. doi: 10.1523/JNEUROSCI.4715-08.2008

Kash, T. L., and Winder, D. G. (2006). Neuropeptide Y and corticotropinreleasing factor bi-directionally modulate inhibitory synaptic transmission in the bed nucleus of the stria terminalis. Neuropharmacology 51, 1013-1022. doi: 10.1016/j.neuropharm.2006.06.011

Kehne, J. H., and Cain, C. K. (2010). Therapeutic utility of non-peptidic CRF1 receptor antagonists in anxiety, depression, and stress-related disorders: evidence from animal models. Pharmacol. Ther. 128, 460-487. doi: 10.1016/j.pharmthera.2010.08.011

Kishimoto, T., Radulovic, J., Radulovic, M., Lin, C. R., Schrick, C., Hooshmand, F., et al. (2000). Deletion of crhr2 reveals an anxiolytic role for corticotropinreleasing hormone receptor-2. Nat. Genet. 24, 415-419. doi: 10.1038/74271

Knobloch, H. S., Charlet, A., Hoffmann, L. C., Eliava, M., Khrulev, S., Cetin, A. H., et al. (2012). Evoked axonal oxytocin release in the central amygdala attenuates fear response. Neuron 73, 553-566. doi: 10.1016/j.neuron.2011.11.030

Kormos, V., and Gaszner, B. (2013). Role of neuropeptides in anxiety, stress, and depression: from animals to humans. Neuropeptides 47, 401-419. doi: 10.1016/j.npep.2013.10.014

Kozicz, T., Yanaihara, H., and Arimura, A. (1998). Distribution of urocortinlike immunoreactivity in the central nervous system of the rat. $J$. Comp. Neurol. 391, 1-10. doi: 10.1002/(SICI)1096-9861(19980202)391:1<1:: AID-CNE1>3.0.CO;2-6

Lawrence, A. J., Krstew, E. V., Dautzenberg, F. M., and Ruhmann, A. (2002). The highly selective CRF(2) receptor antagonist K41498 binds to presynaptic CRF(2) receptors in rat brain. Br. J. Pharmacol. 136, 896-904. doi: 10.1038/si.bjp.0704783

Lebow, M., Neufeld-Cohen, A., Kuperman, Y., Tsoory, M., Gil, S., and Chen, A. (2012). Susceptibility to PTSD-like behavior is mediated by corticotropinreleasing factor receptor type 2 levels in the bed nucleus of the stria terminalis. J. Neurosci. 32, 6906-6916. doi: 10.1523/JNEUROSCI.4012-11.2012

Lewis, K., Li, C., Perrin, M. H., Blount, A., Kunitake, K., Donaldson, C., et al. (2001). Identification of urocortin III, an additional member of the corticotropin-releasing factor (CRF) family with high affinity for the CRF2 receptor. Proc. Natl. Acad. Sci. U.S.A. 98, 7570-7575. doi: $10.1073 /$ pnas. 121165198

Li, W., and Neugebauer, V. (2004a). Block of NMDA and non-NMDA receptor activation results in reduced background and evoked activity of central amygdala neurons in a model of arthritic pain. Pain 110, 112-122. doi: $10.1016 /$ j.pain.2004.03.015

Li, W., and Neugebauer, V. (2004b). Differential roles of mGluR1 and mGluR5 in brief and prolonged nociceptive processing in central amygdala neurons. J. Neurophysiol. 91, 13-24. doi: 10.1152/jn.00485.2003

Lovenberg, T. W., Liaw, C. W., Grigoriadis, D. E., Clevenger, W., Chalmers, D. T., De Souza, E. B., et al. (1995). Cloning and characterization of a functionally distinct corticotropin-releasing factor receptor subtype from rat brain. Proc. Natl. Acad. Sci. U.S.A. 92, 836-840. doi: 10.1073/pnas.92.3.836

Moaddab, M., and Dabrowska, J. (2017). Oxytocin receptor neurotransmission in the dorsolateral bed nucleus of the stria terminalis facilitates the acquisition of cued fear in the fear-potentiated startle paradigm in rats. Neuropharmacology 121, 130-139. doi: 10.1016/j.neuropharm.2017.04.039

Neumann, I. D., Kromer, S. A., Toschi, N., and Ebner, K. (2000). Brain oxytocin inhibits the (re)activity of the hypothalamo-pituitary-adrenal axis in male rats: involvement of hypothalamic and limbic brain regions. Regul. Pept. 96, 31-38. doi: 10.1016/S0167-0115(00)00197-X

Neumann, I., Russell, J. A., and Landgraf, R. (1993). Oxytocin and vasopressin release within the supraoptic and paraventricular nuclei of pregnant, parturient and lactating rats: a microdialysis study. Neuroscience 53, 65-75. doi: 10.1016/0306-4522(93)90285-N

Nie, Z., Zorrilla, E. P., Madamba, S. G., Rice, K. C., Roberto, M., and Siggins, G. R. (2009). Presynaptic CRF1 receptors mediate the ethanol enhancement of GABAergic transmission in the mouse central amygdala. Sci. World J. 9, 68-85. doi: 10.1100/tsw.2009.1

Nomura, M., Saito, J., Ueta, Y., Muglia, L. J., Pfaff, D. W., and Ogawa, S. (2003). Enhanced up-regulation of corticotropin-releasing hormone gene expression in response to restraint stress in the hypothalamic paraventricular nucleus of oxytocin gene-deficient male mice. J. Neuroendocrinol. 15, 1054-1061. doi: 10.1046/j.1365-2826.2003.01095.x
Paxinos, G., and Watson, C. (2009). The Rat Brain in Stereotaxic Coordinates, 6th Edn. Academic Press; Elsevier.

Pedersen, C. A., Caldwell, J. D., Peterson, G., Walker, C. H., and Mason, G. A. (1992). Oxytocin activation of maternal behavior in the rat. Ann. N. Y. Acad. Sci. 652, 58-69. doi: 10.1111/j.1749-6632.1992.tb34 346.x

Perrin, M. H., DiGruccio, M. R., Koerber, S. C., Rivier, J. E., Kunitake, K. S., Bain, D. L., et al. (2003). A soluble form of the first extracellular domain of mouse type 2beta corticotropin-releasing factor receptor reveals differential ligand specificity. J. Biol. Chem. 278, 15595-15600. doi: 10.1074/jbc.M2104 76200

Pollandt, S., Liu, J., Orozco-Cabal, L., Grigoriadis, D. E., Vale, W. W., Gallagher, J. P., et al. (2006). Cocaine withdrawal enhances long-term potentiation induced by corticotropin-releasing factor at central amygdala glutamatergic synapses via CRF, NMDA receptors and PKA. Eur. J. Neurosci. 24, 1733-1743. doi: $10.1111 / j .1460-9568.2006 .05049 . x$

Pow, D. V., and Morris, J. F. (1989). Dendrites of hypothalamic magnocellular neurons release neurohypophysial peptides by exocytosis. Neuroscience 32, 435-439. doi: 10.1016/0306-4522(89)90091-2

Refojo, D., Schweizer, M., Kuehne, C., Ehrenberg, S., Thoeringer, C., Vogl, A. M., et al. (2011). Glutamatergic and dopaminergic neurons mediate anxiogenic and anxiolytic effects of CRHR1. Science 333, 1903-1907. doi: $10.1126 /$ science. 1202107

Risbrough, V. B., Hauger, R. L., Roberts, A. L., Vale, W. W., and Geyer, M. A. (2004). Corticotropin-releasing factor receptors CRF1 and CRF2 exert both additive and opposing influences on defensive startle behavior. J. Neurosci. 24, 6545-6552. doi: 10.1523/JNEUROSCI.5760-03.2004

Ross, H. E., Cole, C. D., Smith, Y., Neumann, I. D., Landgraf, R., Murphy, A. Z., et al. (2009). Characterization of the oxytocin system regulating affiliative behavior in female prairie voles. Neuroscience 162, 892-903. doi: 10.1016/j.neuroscience.2009.05.055

Rouwette, T., Klemann, K., Gaszner, B., Scheffer, G. J., Roubos, E. W., Scheenen, W. J., et al. (2011). Differential responses of corticotropin-releasing factor and urocortin 1 to acute pain stress in the rat brain. Neuroscience 183, 15-24. doi: 10.1016/j.neuroscience.2011.03.054

Sahuque, L. L., Kullberg, E. F., McGeehan, A. J., Kinder, J. R., Hicks, M. P., Blanton, M. G., et al. (2006). Anxiogenic and aversive effects of corticotropinreleasing factor $(\mathrm{CRF})$ in the bed nucleus of the stria terminalis in the rat: role of CRF receptor subtypes. Psychopharmacology 186, 122-132. doi: 10.1007/s00213-006-0362-y

Silberman, Y., Matthews, R. T., and Winder, D. G. (2013). A corticotropin releasing factor pathway for ethanol regulation of the ventral tegmental area in the bed nucleus of the stria terminalis. J. Neurosci. 33, 950-960. doi: 10.1523/JNEUROSCI.2949-12.2013

Sofroniew, M. V. (1983). Morphology of vasopressin and oxytocin neurones and their central and vascular projections. Prog. Brain Res. 60, 101-114. doi: 10.1016/S0079-6123(08)64378-2

Stevens, S. L., Shaw, T. E., Dykhuizen, E., Lessov, N. S., Hill, J. K., Wurst, W., et al. (2003). Reduced cerebral injury in CRH-R1 deficient mice after focal ischemia: a potential link to microglia and atrocytes that express CRH-R1. J. Cereb. Blood Flow Metab. 23, 1151-1159. doi: 10.1097/01.WCB.0000086957.72078.D4

Suda, T., Kageyama, K., Sakihara, S., and Nigawara, T. (2004). Physiological roles of urocortins, human homologues of fish urotensin I, and their receptors. Peptides 25, 1689-1701. doi: 10.1016/j.peptides.2004.03.027

Sun, N., and Cassell, M. D. (1993). Intrinsic GABAergic neurons in the rat central extended amygdala. J. Comp. Neurol. 330, 381-404. doi: 10.1002/cne.903300308

Swanson, L. W., and Sawchenko, P. E. (1983). Hypothalamic integration: organization of the paraventricular and supraoptic nuclei. Annu. Rev. Neurosci. 6, 269-324. doi: 10.1146/annurev.ne.06.030183.0 01413

Takahashi, L. K., Ho, S. P., Livanov, V., Graciani, N., and Arneric, S. P. (2001). Antagonism of $\mathrm{CRF}(2)$ receptors produces anxiolytic behavior in animal models of anxiety. Brain Res. 902, 135-142. doi: 10.1016/S0006-8993(01)02405-2

Valdez, G. R., Zorrilla, E. P., Rivier, J., Vale, W. W., and Koob, G. F. (2003). Locomotor suppressive and anxiolytic-like effects of urocortin 3, a highly selective type 2 corticotropin-releasing factor agonist. Brain Res. 980, 206-212. doi: 10.1016/S0006-8993(03)02971-8 
Van Pett, K., Viau, V., Bittencourt, J. C., Chan, R. K., Li, H. Y., Arias, C., et al. (2000). Distribution of mRNAs encoding CRF receptors in brain and pituitary of rat and mouse. J. Comp. Neurol. 428, 191-212. doi: 10.1002/10969861(20001211)428:2<191::AID-CNE1 >3.0.CO;2-U

Veenema, A. H., and Neumann, I. D. (2008). Central vasopressin and oxytocin release: regulation of complex social behaviours. Prog. Brain Res. 170, 261-276. doi: 10.1016/S0079-6123(08)00422-6

Wang, B., You, Z. B., Rice, K. C., and Wise, R. A. (2007). Stress-induced relapse to cocaine seeking: roles for the $\mathrm{CRF}(2)$ receptor and CRF-binding protein in the ventral tegmental area of the rat. Psychopharmacology 193, 283-294. doi: 10.1007/s00213-007-0782-3
Conflict of Interest Statement: The authors declare that the research was conducted in the absence of any commercial or financial relationships that could be construed as a potential conflict of interest.

Copyright (c) 2018 Martinon and Dabrowska. This is an open-access article distributed under the terms of the Creative Commons Attribution License (CC BY). The use, distribution or reproduction in other forums is permitted, provided the original author(s) and the copyright owner are credited and that the original publication in this journal is cited, in accordance with accepted academic practice. No use, distribution or reproduction is permitted which does not comply with these terms. 